\title{
Influence of tool geometry and numerical parameters when modeling orthogonal cutting of LFRP composites
}

\author{
X. Soldani ${ }^{\text {a }}$, C. Santiuste ${ }^{\mathrm{b}}$, A. Muñoz-Sánchez ${ }^{\mathrm{a}}$, M.H. Miguélez ${ }^{\mathrm{a}, *}$ \\ a Department of Mechanical Engineering, Universidad Carlos III de Madrid, Avda. de la Universidad 30, 28911 Leganés, Madrid, Spain \\ ${ }^{\mathrm{b}}$ Department of Continuum Mechanics and Structural Analysis, Universidad Carlos III de Madrid, Avda. de la Universidad 30, 28911 Leganés, Madrid, Spain
}

Keywords:

Glass LFRP

C. Finite element analysis (FEA)

C. Numerical analysis

E. Cutting

A. Glass fibers

\begin{abstract}
The first objective of this paper is to analyze the influence of mesh size and shape in finite element modeling of composite cutting. Also the influence of the level of energy needed to reach complete breakage of the element is considered. The statement of this level of energy is crucial to simulate the material behavior. On the other hand geometrical characteristics of the tool have significant influence on machining processes. The second objective of the present work is to advance in the knowledge concerning tool geometry and its effect in composite cutting.

A two-dimensional finite element model of orthogonal cutting has been developed and validated for Glass LFRP composite, comparing with experimental results presented in scientific literature. It was demonstrated that both numerical parameters and tool geometry influence the predicted chip morphology and machining induced damage.
\end{abstract}

\section{Introduction}

Long Fiber Reinforced Polymer (LFRP) composites are suitable for a wide range of applications in aeronautical, automotive, marine and sporting industries. Their attractive physical and mechanical properties lead to increasing application fields of this materials family. The components based on LFRP composites are usually made to the final size of the desired product; however, some machining operations are commonly needed to achieve work-piece requirements.

Machining operations on LFRP composites in industry involves considerable difficulties due to the presence of long fibers and the risk of inducing damage during the cutting process [1].

Experimental research in the field of composite cutting is not only expensive in terms of time and cost. Also the health hazards associated to the presence of fibers in the chip removed reduces the possibility to carry out extensive experimental research on machining of LFRP composites.

The interpretation of results is also difficult due to the complexity of the cutting process itself and because of the anisotropy of the composite. Industrial machining processes involves oblique cutting, however, orthogonal cutting is commonly the objective of simulations in machining numerical studies, due to its simplicity and utility to obtain information about difficult to measure variables. Despite of its limitations it is possible to obtain interesting information concerning, for instance, chip morphology, subsurface

\footnotetext{
* Corresponding author. Tel.: +34 9162494 02; fax: +34 916249430 .

E-mail address: mhmiguel@ing.uc3m.es (M.H. Miguélez).
}

damage, influence of fiber orientation and the role of tool geometry. On the other hand the development of complex models for oblique cutting requires the use of three dimensional approaches involving elevated computational cost. It is necessary to advance in the knowledge of simplified cutting process prior to develop three dimensional approaches.

The necessity to simplify the process in order to understand the basic phenomena involved in the cutting operation, has motivated the development of several works focused on the study of orthogonal cutting of LFRP composites [2-12].

Experimental works presented in [2-4] have studied the effect of fiber orientation, depth of cut, rake angle and cutting edge radius. Experimental results obtained in these works have been widely used to validate numerical models in scientific literature.

Also Finite Element (FE) has been used to analyze orthogonal cutting of LFRP composites using macro and micro mechanical approaches [5-13].

Combined micro-macro approach was applied to analyze orthogonal cutting of composite in [5,6], obtaining good prediction of cutting forces. Micro mechanical modeling of both glass and carbon fiber reinforced polymer composite has been developed recently in [7]. De-cohesion phenomena in matrix-fiber interface was analyzed and it was demonstrated the influence of the fiber orientation on the failure mechanisms.

Macro-mechanical approaches have used to model the composite as an anisotropic homogeneous material. Two dimensional approaches commonly involve the hypothesis of unidirectional fiber orientation. The earliest study of orthogonal cutting of unidirectional composites based on finite element was presented by Arola 
and Ramulu [8]. Failure mechanism based on fiber-matrix cracking was implemented and the influence of fiber orientation for different LFRP composites was analyzed by Ramesh et al. [9]. It was found that the load needed to induce failure depended on the fiber orientation. Both two-dimensional (2D) and three-dimensional (3D) approaches were used by Mahdi and Zhang [10,11] to simulate composite cutting. 2D analysis reproduced an equivalent homogeneous material predicting cutting forces of LFRP composite depending on the fiber orientation. 3D approach simulated a composite cell based on perfectly bonded constituents (fiber and matrix). The influence of tool geometry on cutting forces and subsurface damage was analyzed by Arola et al. [12] focusing on orthogonal machining of unidirectional LFRPs. In general these studies showed good approximation to experimental cutting forces however, thrust forces were poorly predicted. In a recent numerical work developed by the authors [13], the mechanism of chip formation of both glass and carbon LFRP composites have been compared.

A new approach of modeling of orthogonal cutting of carbon LFRP using discrete element method (DEM) has been presented in [14]. The observation of the chip formation using a high speed video camera made possible to validate qualitatively the results of numerical simulation by discrete elements. A recent work [15] has focused on the development of the analytical foundation for orthogonal cutting of FRP laminates. The study focused on the understanding of the implications of the subsurface stresses and associated damage during machining, provided a framework for studying the subsurface stress fields during edge trimming of FRPs.

The influence of numerical parameters of the model (such as mesh size and shape) has been extensively analyzed in different works focusing on metal cutting (see for instance Refs. [16-18]). Although macroscopic results such as cutting forces are not considerably affected by these parameters, the local results depending on localization phenomena are strongly dependent on mesh size and shape. For instance, the prediction of segmentation during cutting of thermo-resistant alloys can be achieved with Lagrangian formulation when an appropriate mesh is designed $[18,19]$.

Despite of the interest to properly define size and mesh of the numerical model, it is not easy to found works analyzing the effect of numerical parameters when simulating composite cutting. The first objective of this paper is to study the influence of mesh size and shape in cutting forces, chip morphology and damage. Also the influence of the level of energy needed to reach complete breakage of the element is considered. The statement of this level of energy is crucial to simulate the material behavior: when low level of energy is implemented the element is eroded just after the damage onset, while high level of energy allows high deformation of the element before total breakage. Thus it is possible to distinguish between ductile composite materials, showing progressive failure; and brittle composite materials, presenting sudden breakage, not only in machining processes, also when experiencing other dynamic loads [13]. Although it could not be considered a purely numerical parameter, since it is representative of mechanical behavior of the composite, it is difficult to find precise information about its value, and thus it is sometimes used as a tuning parameter for modeling process.

On the other hand geometrical characteristics of the tool have significant influence on machining processes. The rake angle is related with the robustness of the tool and also with the surface quality of the workpiece. Tool geometry was found to have significant influence on the frequency characteristics of measured force signal in orthogonal cutting of glass fiber reinforced composites [20]. The cutting edge radius, always larger than zero even in the case of a sharp new tool, also influences the cutting processes. The rounding of the tool nose has been observed during orthogonal cutting of unidirectional glass-reinforced plastics when the cutting speed was very low [21]. The influence of cutting edge radius is especially important when small values of the feed are considered and has been extensively studied in metal cutting. The second objective of the present work is to advance in the knowledge concerning tool geometry and its influence in composite cutting.

The work is focused on orthogonal cutting of LFRP. A twodimensional finite element model has been developed. The model was validated for Glass LFRP comparing with experimental results presented in scientific literature [3]. The description of the model and the study of the results sensitivity with the mesh size are presented in Section 2. Numerical results concerning the influence of mesh orientation, breakage energy and tool geometry are summarized and discussed in Section 3. Conclusions of the work are presented in Section 4.

\section{Numerical modeling}

\subsection{Description of the basic model: geometry, contact, meshing and analysis}

The basic model is described in detail in [13] and it is briefly summarized in this section. The plane stress model was developed using the commercial finite element code ABAQUS/Explicit. Dynamic explicit analysis was performed with plane stress, quadrilateral, linearly interpolated, elements, with reduced integration and automatic hourglass control (CPS4R in ABAQUS/Explicit notation [22]).

Geometry and boundary conditions of the numerical model are shown in Fig. 1. For the basic model values of depth of cut and rake angle, clearance angle and cutting edge radius were coherently defined with those used in [3] in order to validate predicted numerical results. Cutting speed does not influence numerical results because of the model assumed for the workpiece behavior. Rake angle was equal to $5^{\circ}$ in the basic model and it was also changed to $0^{\circ}$ and $10^{\circ}$ in order to analyze its influence on the numerical results.

The cutting length was equal to $2 \mathrm{~mm}$, large enough to reach cutting force stabilization, in order to analyze not only the chip initiation phenomena, but also the evolution of cutting [13]. The simulation of longer cutting length increases significantly the computational cost without changes in the level of cutting force predicted. This cutting length would not be enough to reach steady state conditions concerning thermal issues but the numerical model does not involve thermal analysis.

Cutting edge radius $(0.05-0.15 \mathrm{~mm})$ and feed $(0.1-0.2 \mathrm{~mm})$ were varied in the study, however, the initial values (feed equal to $0.2 \mathrm{~mm}$ and cutting edge radius equal to $0.05 \mathrm{~mm}$ ) were used in most figures of the paper and when it is not indicated other value. Feed rate corresponds with the range of values commonly used in milling, see for instance the work of Girot et al. [23].

Interaction between workpiece and tool was modeled by using surface-node surface contact available in ABAQUS/Explicit [18]. Friction at the interface is one of the hardest phenomena to simulate in machining. Only few works focus on the identification of friction coefficients between FRP composites and cutting tool materials, and consequently few data are available for different cutting tool/composite interaction [24]. In the present work, a constant coefficient of friction equal to 0.5 at the tool/workpiece interface was assumed as proposed in [25].

The mesh of workpiece was refined at the zone surrounding the tool tip in order to model accurately the evolution of damage associated to chip initiation and evolution. In the basic model the mesh was defined automatically by the code pre-processor (unstructured mesh in Fig. 2) without any predefined structure.

The explicit integration scheme used in the calculation requires very small time step, typically around $10^{-10}-10^{-9} \mathrm{~s}$, leading to 


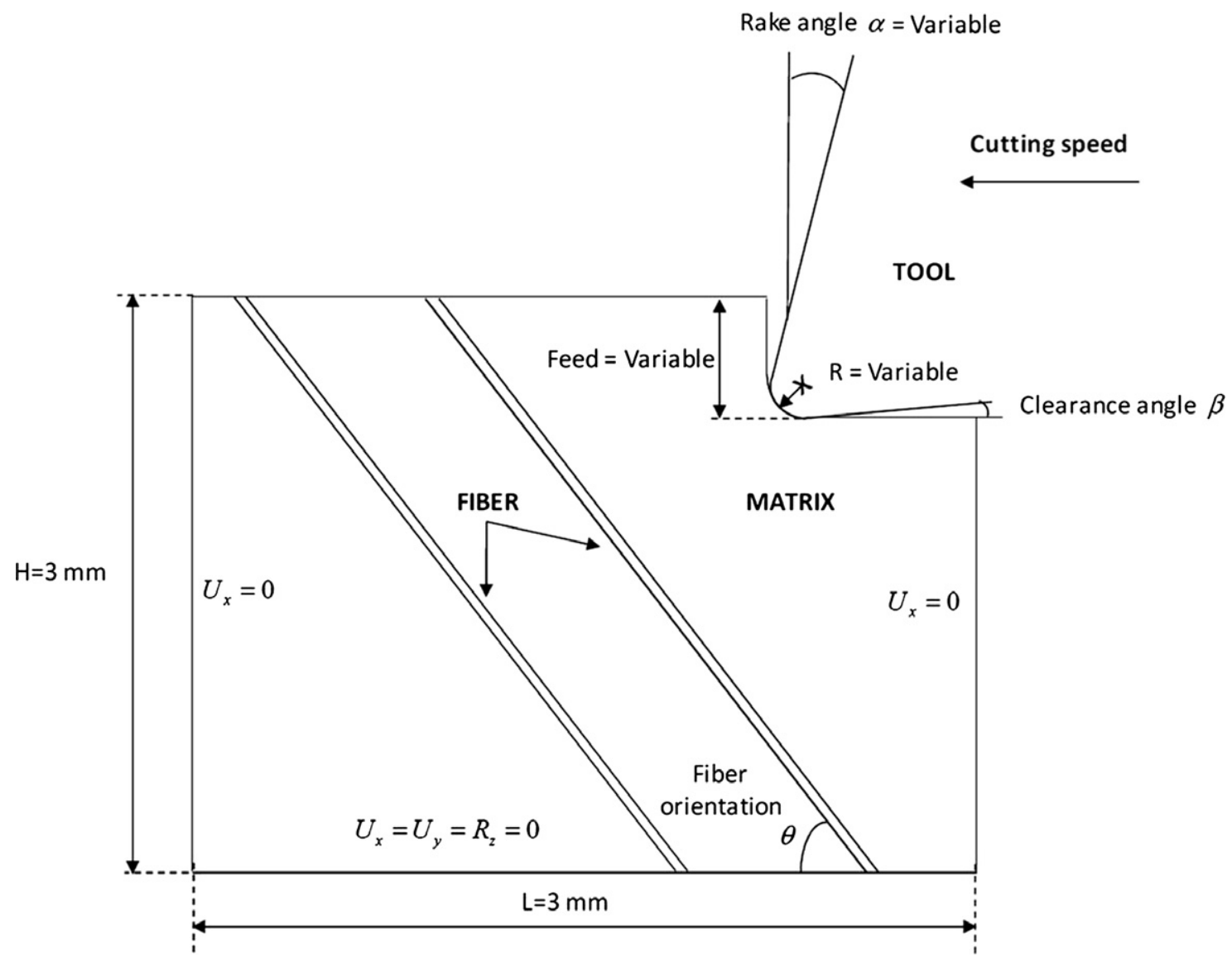

Fig. 1. Scheme and dimensions of the model.

large calculation time. Thus the element size should be defined under the point of view of both accuracy and time efficiency of the computing process.

\subsection{Element size and mesh orientation}

The mesh of the basic model was automatically generated by the code for a given medium size of the element. In order to control the influence of the element size, the mesh was also structured. Three different sizes of element were considered: $4 \times 4,7 \times 7$ and $12 \times 12 \mu \mathrm{m}$. Different meshes are shown in Fig. 2, compared with the unstructured mesh used in the basic model.

The orientation of the mesh was also modified to analyze the possible dependence of the damage propagation with the inclination of the mesh. In order to define the element orientation only quadrilateral elements should be used in the structured mesh. Fig. 3 shows both cases considered: mesh inclination equal to $0^{\circ}$ and $45^{\circ}$.

\subsection{Materials and damage modeling}

The tool was assumed to be rigid. The workpiece material was Glass FRP composite modeled with an elastic behavior up to failure, taking into account the anisotropy of the material. The failure of composite material could be predicted using different criteria. Lasri et al. compared in [25] maximum stress, Hoffman and Hashin criteria in the prediction of cutting force and failure modes in orthogonal cutting on glass fiber composite. The results predicted with Hashin criteria were closer to experiments and were able to distinguish between main failure modes during the chip formation.
To predict the failure of the composite material, damage initiation criteria based on Hashin's theory $[26,27]$ was used including a degradation procedure considering the energy needed for breakage. The composite failure criteria proposed by Hashin and Rotem [26] combines the advantages of Hoffman criterion, considering the interactions between normal and shear stresses, and the advantages of maximum stress criteria, including four failure modes: fiber tensile failure, fiber compressive failure, matrix cracking, and matrix crushing (Eqs. (1)-(4)).- Fiber tension $\left(\sigma_{11}>0\right)$ :

$d_{f}^{t}=\left(\frac{\sigma_{11}}{X^{T}}\right)^{2}+\alpha\left(\frac{\tau_{12}}{S^{L}}\right)^{2} \leqslant 1$

- Fiber compression $\left(\sigma_{11}<0\right)$ :

$d_{f}^{c}=\left(\frac{\sigma_{11}}{X^{c}}\right)^{2} \leqslant 1$

- Matrix cracking $\left(\sigma_{22}>0\right)$ :

$d_{m}^{t}=\left(\frac{\sigma_{22}}{Y^{T}}\right)^{2}+\left(\frac{\tau_{12}}{S^{L}}\right)^{2} \leqslant 1$

- Matrix crushing $\left(\sigma_{22}<0\right)$ :

$d_{m}^{c}=\left(\frac{\sigma_{22}}{2 S^{T}}\right)^{2}+\left[\left(\frac{Y^{C}}{2 S^{T}}\right)^{2}-1\right] \frac{\sigma_{22}}{Y^{C}}+\left(\frac{\tau_{12}}{S^{L}}\right)^{2} \leqslant 1$

where $\sigma_{11}$ denotes the stress in fiber direction, $\sigma_{22}$ the stress in transverse direction, and $\sigma_{12}$ the in-plane shear stress. The rest of variables in Eqs. (1)-(4) are material characteristics listed in Table 1. These Glass LFRP mechanical properties are taken from [3]. 


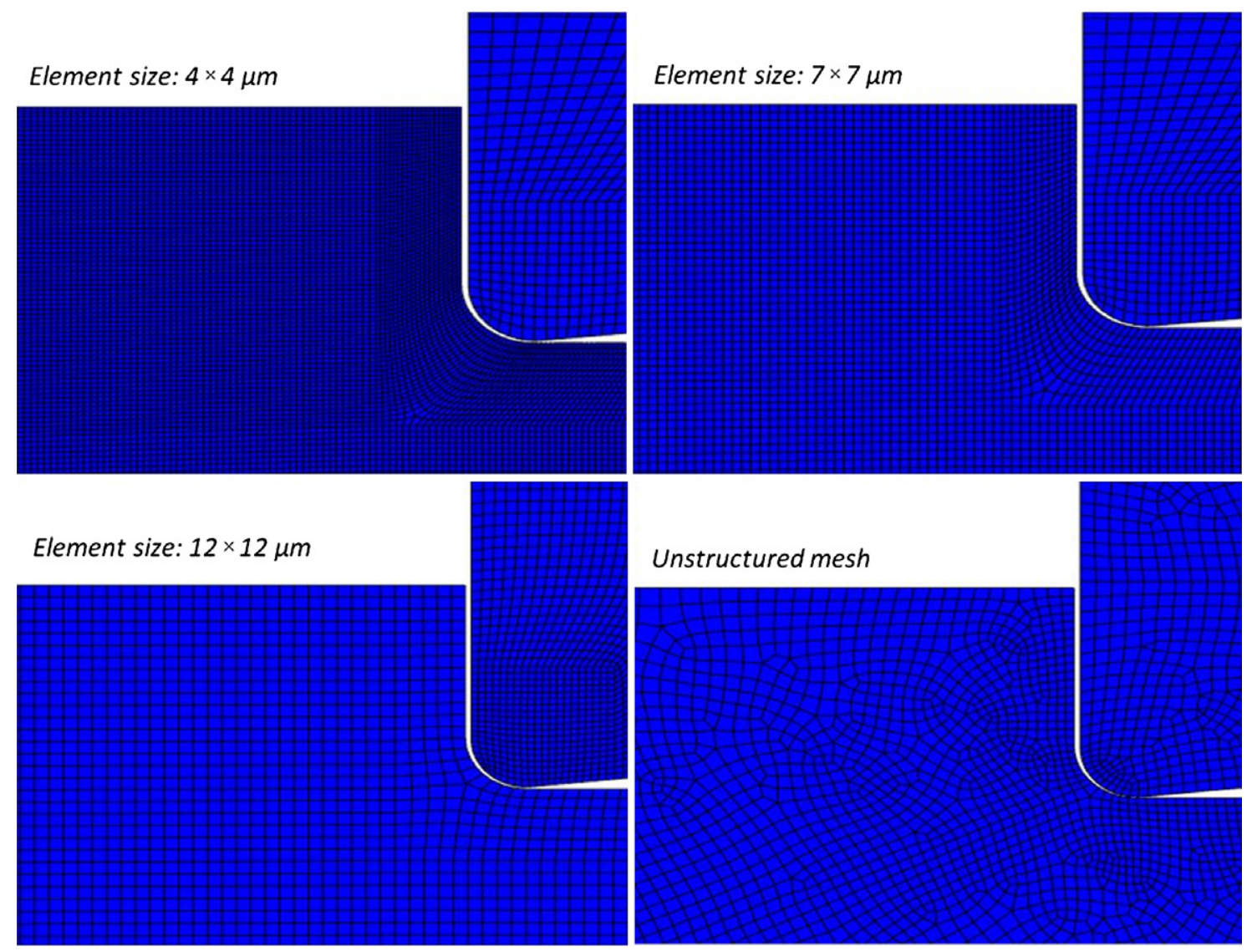

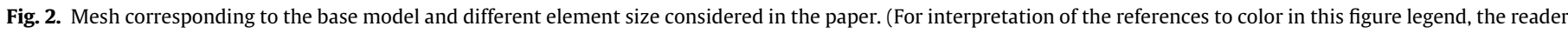
is referred to the web version of this article.)

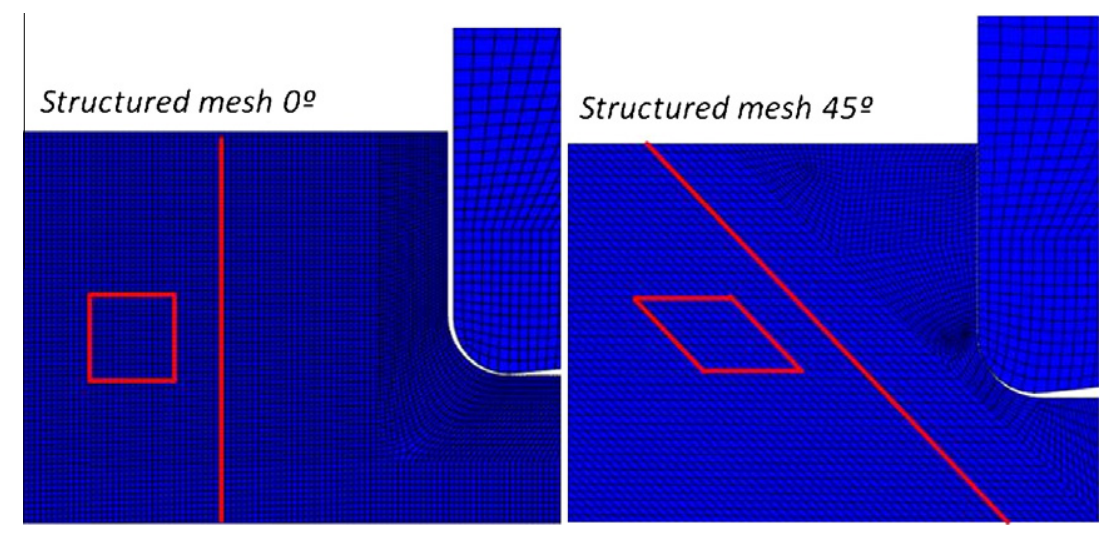

Fig. 3. Mesh orientation at $0^{\circ}$ and $45^{\circ}$. (For interpretation of the references to color in this figure legend, the reader is referred to the web version of this article.)

Under a given load, the stresses at each integration point in the workpiece were computed. Then, the failure modes were evaluated; if any failure criterion reached the unity (the onset of damage corresponds with the maximum level of equivalent stress $\sigma_{c}$, see Fig. 4), the elastic properties at that element had to be degraded according to the failure mode. Fiber failure, produced degradation of both longitudinal and shear modulus, and matrix failure produces degradation of transverse and shear modulus. Damage initiation refers to the onset of degradation at a material point and it is used to predict rupture and subsequent deletion of the damaged element.

The degradation of material properties was modeled decreasing the level of the properties related with stiffness equal to zero. However, the zero value was not stated immediately after the initiation of damage; the reduction of the stiffness coefficients is controlled by damage variables that might assume values between

Table 1

Mechanical properties for GFRP [3].

\begin{tabular}{ll}
\hline Mechanical properties & Glass FRP \\
\hline Longitudinal modulus, $E_{1}(\mathrm{GPa})$ & 48 \\
Transverse modulus, $E_{2}(\mathrm{GPa})$ & 12 \\
In-plane shear modulus, $G_{12}(\mathrm{GPa})$ & 6 \\
Major Poisson 's ratio, $v_{12}$ & 0.28 \\
Longitudinal tensile strength, $X_{T}(\mathrm{MPa})$ & 1200 \\
Longitudinal compressive strength, $X_{C}(\mathrm{MPa})$ & 800 \\
Transverse tensile strength, $Y_{T}(\mathrm{MPa})$ & 59 \\
Transverse compressive strength, $Y_{C}(\mathrm{MPa})$ & 128 \\
Shear strength, $S(\mathrm{MPa})$ & 25
\end{tabular}




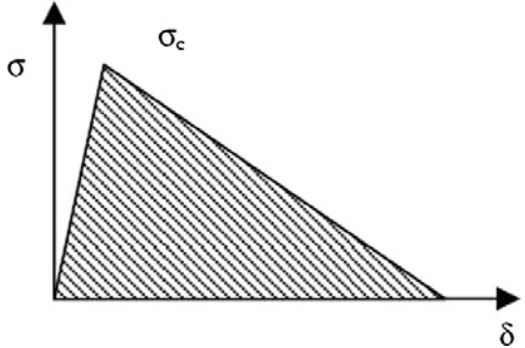

Fig. 4. The value of energy necessary to break the element [22].

zero (undamaged) and one (fully damage condition for the mode corresponding to this damage variable). The evolution law of the damage variable in the phase subsequent to damage initiation phase is based on the fracture energy dissipated during the damage process, $G_{I}$. This evolution law is a generalization of the approach proposed by Camanho and Dávila [28] for modeling interlaminar delamination using cohesive elements. The statement of this energy level is crucial to simulate the material behavior: when low energy level is implemented, the element is eroded just after the damage onset, while high level of energy allows high deformation of the element before total breakage. Thus it is possible to distinguish between ductile composite materials, showing progressive failure; and brittle composite materials, presenting sudden breakage, not only in machining processes, also when experiencing other dynamic loadings. In general, the GFRPs could be included in the former category [29].

The reference value of energy necessary to break the element was initially stated equal to $400 \mathrm{~J} / \mathrm{m}^{2}$. This parameter represents the area under the stress-displacement curve $(\sigma-\delta$, see Fig. 4$)$, being the displacement obtained as the strain at the element multiplied by the characteristic length of the element (a typical length of a line across an element). $\sigma_{c}$ is the value of equivalent strain corresponding to the onset of damage in the element.

The value used in the basic model, was changed to $200 \mathrm{~J} / \mathrm{m}^{2}$ and $600 \mathrm{~J} / \mathrm{m}^{2}$ in order to analyze the influence of the material ductility in the predicted results. However, since the aim of the study is to reproduce more accurately the physical phenomenon associated to the breakage of the composite, also different energy values were stated for each failure mode: fiber tensile failure, fiber compressive failure, matrix cracking, and matrix crushing. On the other hand, these values might not always be easily measured experimentally or available in the literature. It was assumed that the stiffness

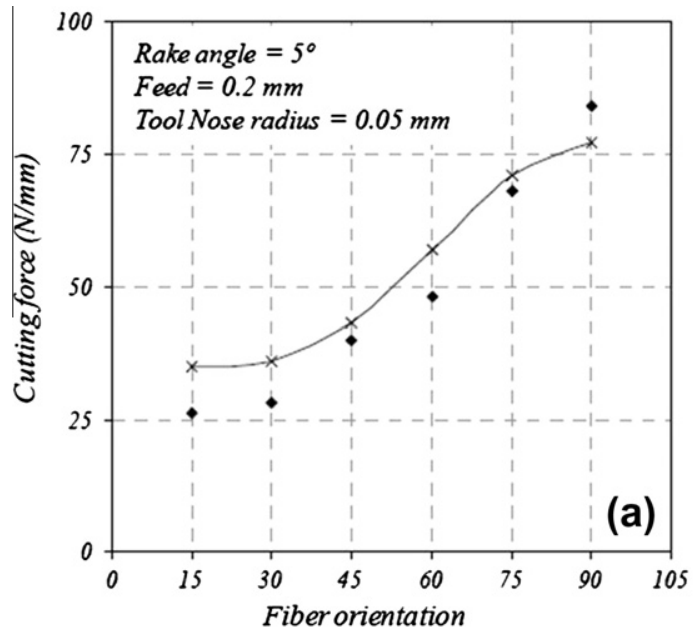

reduction associated with damage due to compressive loads is different from the stiffness reduction associated with tensile loads. The main reason is the fact that crack surfaces under tensile loading are traction free, whereas under compressive loading they can still carry some load. Each failure mode should be associated with a different energy level, in the same way that it is associated to a different expression for the failure criterion. This approach was firstly introduced by Camanho and Matthews [30]; the residual stiffness after the onset of damage associated to failure was respectively: 7\% (fiber tension); 14\% (fiber compression), 20\% (matrix cracking) and $40 \%$ (matrix crushing).

According to this work, fiber failure is brittle and the residual stiffness reduced, more in the case of fiber tension, because of the resistance of the matrix in the case of fiber compression failure. The matrix cracking failure should be ductile corresponding to the behavior of the polymeric matrix. Finally, the matrix crushing failure is associated with improved levels of residual stiffness due to the ability of undergo compressive loads despite of fracture initiation. In this paper the values of energy have been adapted to different mechanisms associated to each type of failure mode: $105 \mathrm{~J} / \mathrm{m}^{2}$ (fiber tension); $200 \mathrm{~J} / \mathrm{m}^{2}$ (fiber compression), $300 \mathrm{~J} / \mathrm{m}^{2}$ (matrix cracking) and $600 \mathrm{~J} / \mathrm{m}^{2}$ (matrix crushing).

On the other hand different fiber orientations (see Fig. 1), $\theta$ equal to $0^{\circ}, 15^{\circ}, 30^{\circ}, 45^{\circ}, 60^{\circ}, 75^{\circ}$ and $90^{\circ}$, were considered in each case.

\subsection{Experimental validation of the model}

In a previous work [13] the model based on unstructured mesh, with rake angle equal to $5^{\circ}$, was validated comparing with the experimental and numerical data given in the Refs. $[3,25]$. The maximum peak value of both cutting force and thrust force at the cutting time corresponding to complete chip formation, were obtained for the different fiber orientations considered. Maximum values of cutting force obtained with the model proposed in [25], showed good accuracy when compared with previous numerical results in scientific literature. However, thrust force presented significant differences between predicted and experimental results. It should be noted the difficulty to accurately model the thrust force, even in the well-known case of metallic workpiece. The model proposed in the previous work improved the accuracy of the thrust force prediction presented in [25]. This fact could be related with the characteristics of the normal and tangential contact imposed at the interface workpiece-tool.

Comparison between predicted forces using unstructured mesh and experimental values given in [3] are presented in Fig. 5. The

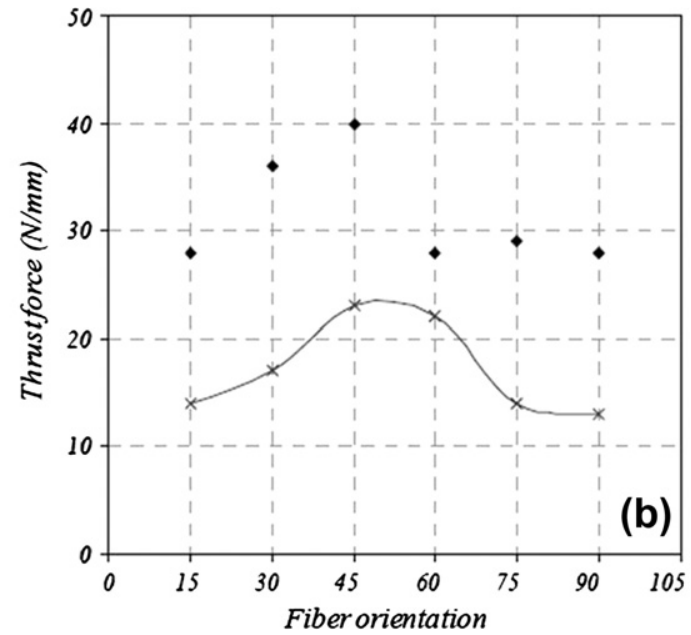

Fig. 5. Cutting (a) and thrust (b) forces vs. fiber orientation. Comparison between numerical results (lines) and experimental measurement [3]. 


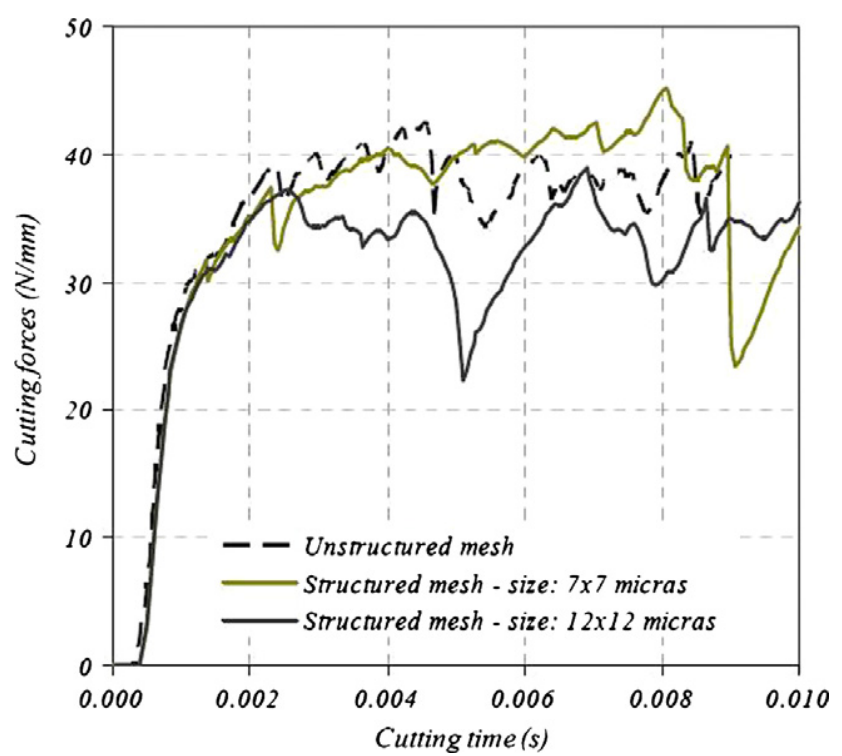

Fig. 6. Influence of element size in force evolution with cutting time (fiber orientation $45^{\circ}$ ). (For interpretation of the references to color in this figure legend, the reader is referred to the web version of this article.)

validation procedure is extended using also the structured mesh and the rake angle equal to $0^{\circ}$ and $10^{\circ}$ in the following sections.

\subsection{Influence of element size and meshing structure}

The shape and size of initial mesh developed in [13] was modified: the mesh was structured (see Fig. 2) and the element size was varied with the values $4 \times 4,7 \times 7$ and $12 \times 12 \mu \mathrm{m}$. Structured mesh gave slightly better approximation to experimental values of forces although there was little influence of the element size on the cutting forces (see Fig. 6).

However, the extension of damage was strongly dependent on the mesh size. Firstly it is worth to note that the understanding of chip evolution process (initiation and complete chip formation) needed the analysis of all composite damage modes. In the previous work [13] it was demonstrated that while fiber failure modes are almost negligible, matrix suffered both significant compression and tensile damage. The matrix presented lower failure stress, being in general matrix crushing (compressive) more extended than matrix cracking in the zone ahead and under the tool tip. Beneath the machined surface the matrix cracking (tensile) mode is usually more significant and the penetration is deeper than crushing damage. Thus, in the following, only matrix failure modes are presented, since they are prevalent when compared with fiber failure modes.

In Fig. 7 shows the damage contours for different values of element size considered. Also the use of structured or unstructured mesh seems to have influence on damage prediction. On one hand it is not easy to control the element size when the automatic meshing of the code is used: although medium element size is stated, some elements are much smaller. On the other hand it is not possible to control the orientation of the elements: it will be shown later in the paper the influence of this inclination angle of the mesh in the numerical results.

Concerning the sensibility of the model with the element size, there were differences between the model with element size equal to $12 \mu \mathrm{m}$ and with the element size equal to $7 \mu \mathrm{m}$. However, the mesh with element size equal to $4 \mu \mathrm{m}$ did not show significant differences with those obtained with element size $7 \mu \mathrm{m}$. The element size is critical for the computational cost of the simulation solved with an explicit integration scheme. The election of the element

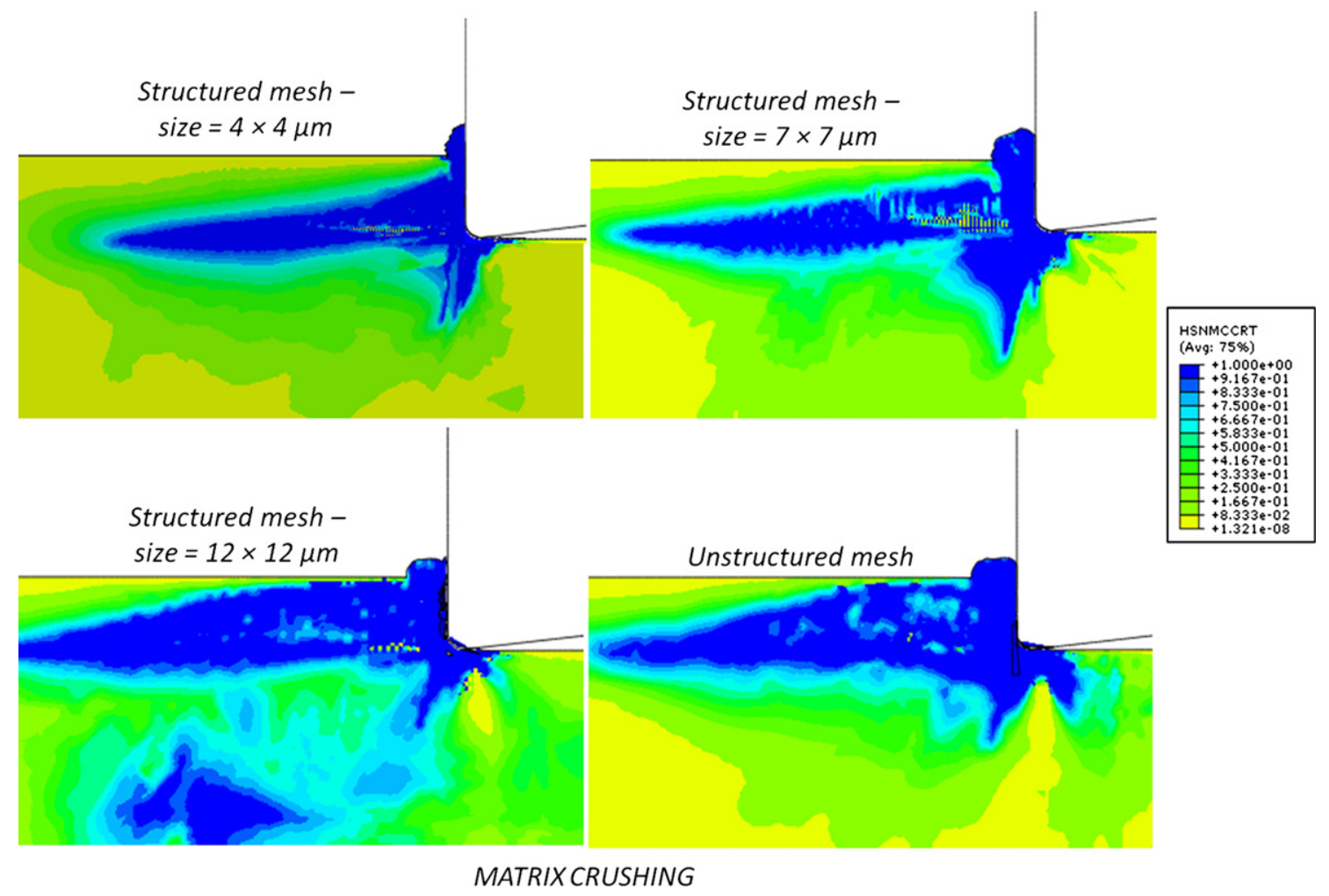

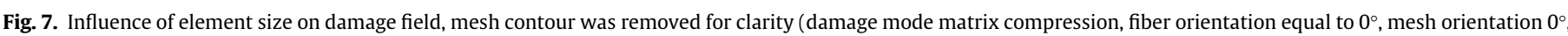

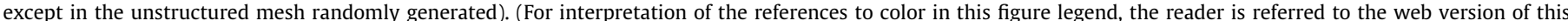
article.) 

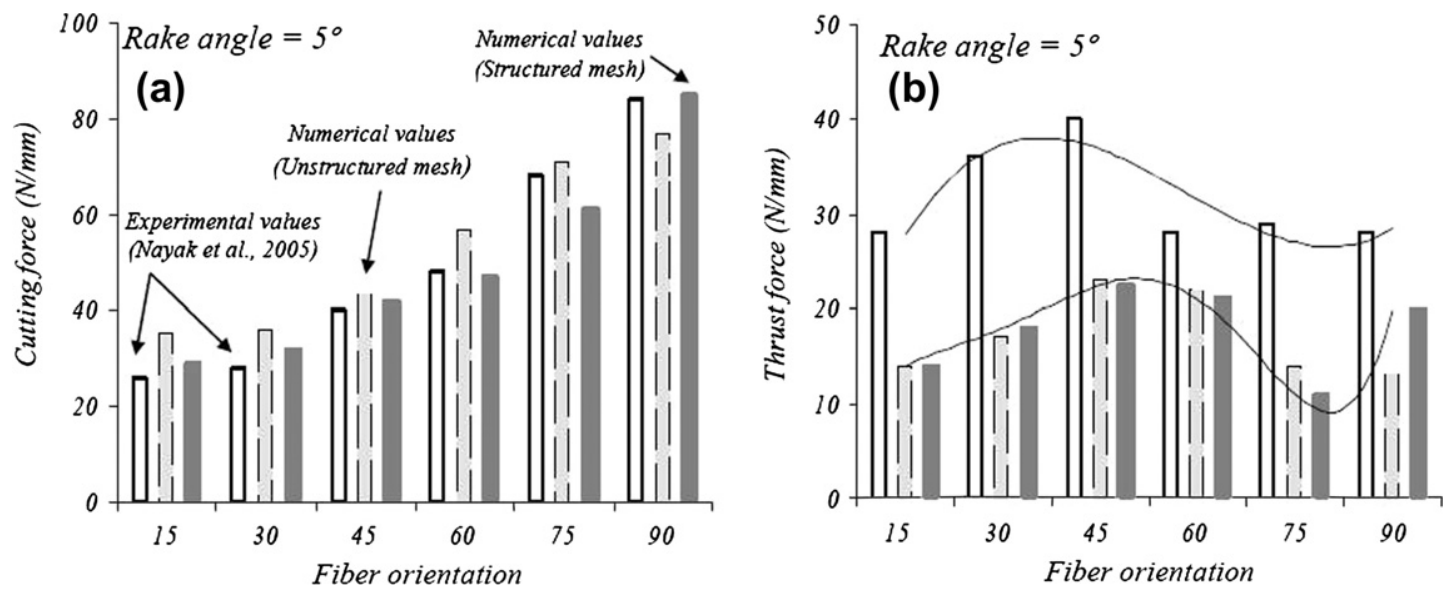

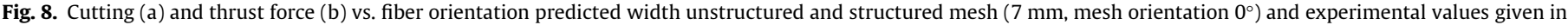
[3] for rake angle equal to $5^{\circ}$.

size should be stated ensuring equilibrium between computational efficiency and precision of the model.

In the following, all calculations are based on element size equal to $7 \times 7 \mu \mathrm{m}$ and structured mesh, just to ensure the comparability between the obtained results: influence of orientation, energy and geometrical parameters of the tool.

\subsection{Extension of validation}

Numerical results obtained with the modified mesh were compared with those given by Nayak et al. [3]. The rake angle was stated equal to $5^{\circ}$, both unstructured and structured with element size equal to $7 \times 7 \mu \mathrm{m}$ meshing were considered. Firstly the cutting and thrust forces were compared in Fig. 8. Both models based on unstructured and structured mesh showed reasonably accuracy in the prediction of cutting and trust forces. The use of a structured mesh improved slightly the predictions in the case of fiber orientation lying in the range $15^{\circ}-60^{\circ}$.

\section{Numerical results and discussion}

\subsection{Mesh orientation}

With the objective of analyzing the effect of mesh inclination on the numerical results, the mesh structured horizontally (size $7 \times 7 \mu \mathrm{m}$ ), was modified giving an inclination angle equal to $45^{\circ}$ (see Fig. 3). This configuration of the mesh has been used in simulation of metal cutting for the analysis of segmentation $[18,19]$. In that case, the best configuration for modeling localization is imposing an angle of inclination of the mesh close to the shear angle. No study of the influence of mesh configuration has been found concerning macroscopic modeling of composite cutting. However, it is well known that the damage distribution is strongly influenced by the fiber orientation and tends to extend along the fiber. It seems to be interesting to link the fiber angle and the mesh inclination, thus simulations with fiber angle equal to $0^{\circ}, 45^{\circ}$ and $90^{\circ}$, were performed with horizontal and mesh inclined to $45^{\circ}$.

As was explained in Section 2 concerning model development, plane stress, quadrilateral, linearly interpolated, elements, with reduced integration and automatic hourglass control (CPS4R) were used in the analysis. The reduced integration scheme is based on the uniform strain formulation [31]. In this method, the element strain is assumed to be given by the average strain over the element. Since the elements involved are constant-strain elements, they are unable to resolve the corresponding strain gradient in their interiors. Hashin failure criteria (Eqs. (1)-(4)) are formulated in local axis coincident with fiber orientation (direction 1) and orthogonal (direction 2). The failure criterion depends on the strain through the stresses and thus, the damage prediction is influenced by the orientation of the element. It should be noticed that when unstructured mesh is considered and the elements are randomly oriented the damage propagation along fiber direction is more difficult. In contrast, the strain field can vary from one to the next across the element boundary, facilitating the resolution of strain gradients associated with damage propagation in the case of parallel mesh. In consequence the predicted damage is affected when the orientation of the mesh is coincident with the orientation of the fiber (see damage fields in Fig. 9) and tends to extend further in both directions: the fiber and orthogonal.

\subsection{Influence of energy needed for breakage}

As was explained before, the energy needed to complete breakage of one element, being a parameter characterizing the ductility of the composite, was varied from 200, 400 and $600 \mathrm{~J} / \mathrm{m}^{2}$ and also energy variable with the damage mode was implemented.

The forces are not clearly dependent on the level of energy. For fiber angle equal to $0^{\circ}$ and $45^{\circ}$, the cutting forces showed approximately the same value irrespective of the energy value. For the fiber angle equal to $90^{\circ}$ the cutting force was slightly increased with the energy value.

However, both the crushing and cracking damages increased with the increment of energy required for breakage causing subsequent enhancement of the material ductility (see Fig. 10). When the onset of damage is induced in an element, it is deformed up to the level of energy allowed. Thus the lower the value of energy (brittle composite), the greater the trend to originate catastrophic failure with no progression of the damage: the elements do not suffer significant deformation, thus they break just after the damage onset, restraining the damage extension on the workpiece [28]. Under the point of view of damage extension, it is more favorable the brittle behavior, since enhanced ductility of the material is related with increased level of damage.

The mechanism of chip formation is also highly sensitive to the critical level of energy. The lower value of energy $\left(200 \mathrm{~J} / \mathrm{m}^{2}\right)$ originates a small chip and the deformation of the mesh is concentrated in a narrow area around the primary zone (approximately parallel to the fiber orientation). Similar chip morphology can be observed in [14] in the orthogonal cutting of CFRP, it is worth to note that carbon composite exhibits brittle behavior that should be 


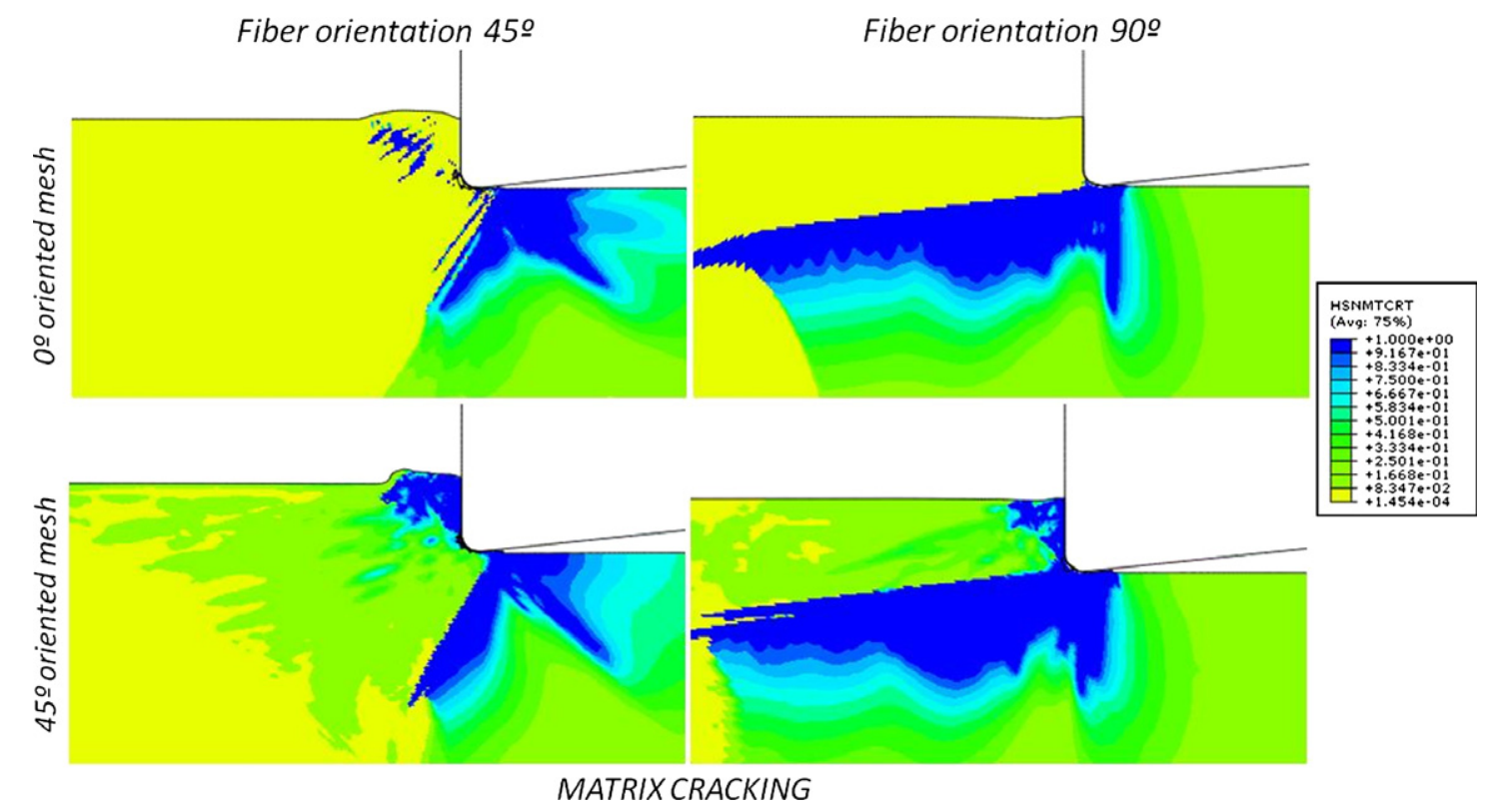

Fig. 9. Influence of mesh orientation on damage distribution. (For interpretation of the references to color in this figure legend, the reader is referred to the web version of this article.)

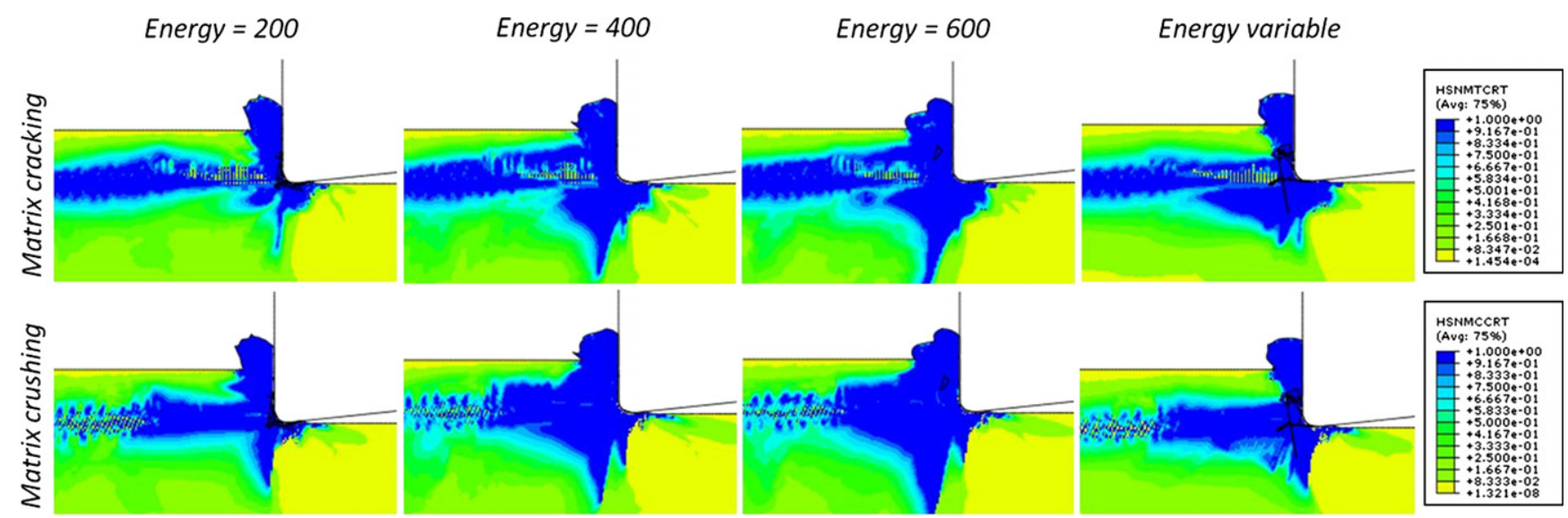

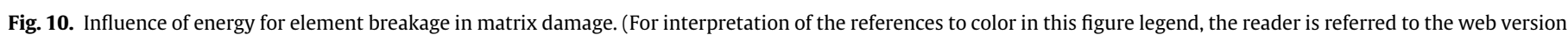
of this article.)

represented with low value of energy. The width of primary zone increases for increasing levels of energy, at the same time the extension of the damage increases. The highest value of the energy corresponds with severe deformation at the primary zone, the chip is not segmented and subsequent chip is originated with no breakage and erosion of any elements. The damage extends in a larger area both ahead the tip and beneath the machined surface. Energy, variable with the damage mode $\left(300 \mathrm{~J} / \mathrm{m}^{2}\right.$ (matrix cracking) and $600 \mathrm{~J} / \mathrm{m}^{2}$ (matrix crushing), leads to an intermediate configuration between brittle and ductile behavior.

\subsection{Influence of rake angle}

Simulations were also carried out with rake angle equal to $0^{\circ}$ and $10^{\circ}$ with both unstructured and structured mesh with element size equal to $7 \times 7 \mu \mathrm{m}$. With the aim to validate numerical results obtained in this work, cutting and thrust forces are presented in Fig. 11 with experimental results obtained from Ref. [3] for a rake angle equal to $10^{\circ}$ (no experimental data for thrust force were available for the case rake angle $=0^{\circ}$ in the Ref. [3]).
The values predicted with the structured mesh are closer to experimental values than those obtained with the coarse mesh.

The cutting forces obtained for the different values of rake angle considered are presented in Fig. 12. In general, the smaller the rake angle the higher the force level. The differences are especially significant in the case of a rake angle equal to $0^{\circ}$. It is well known the influence of rake angle on cutting force in metal cutting. Small values of rake angle are related with robustness of the tool and thus are indicated for hard machining operations, however, the generation of compressive fields of stress ahead the tip and beneath the machined surface are commonly related with enhanced cutting forces and worst surface quality. In case of composite cutting, the same trend is observed for values of fiber angle orientation from $0^{\circ}$ to $75^{\circ}$. However, for the fiber angle equal to $90^{\circ}$, this trend is not observed. This behavior could be due to the special mechanism of chip generation observed when the fibers are perpendicular to the cutting direction. In this case, the influence of the rake angle it is not clear since the fibers break in the zone ahead the tip and the elements are removed without significant influence on the cutting force. 

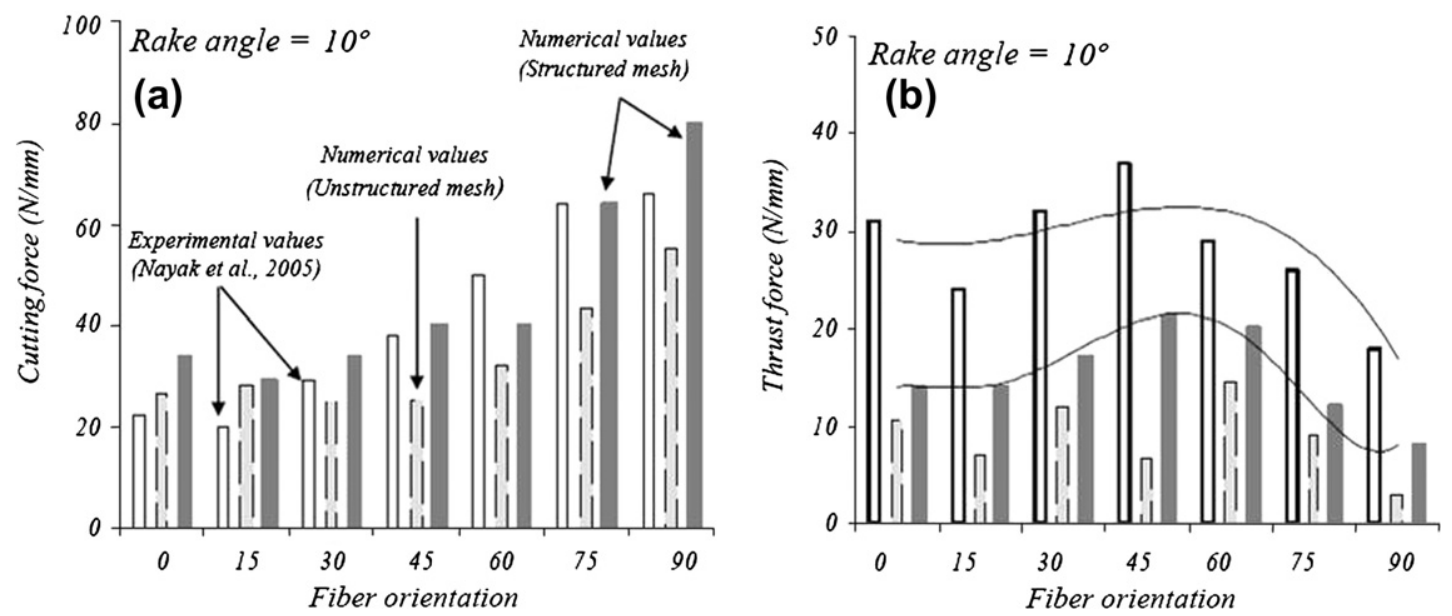

Fig. 11. Comparison between calculated and measured [3] cutting and thrust force with cutting angle equal to $10^{\circ}$.

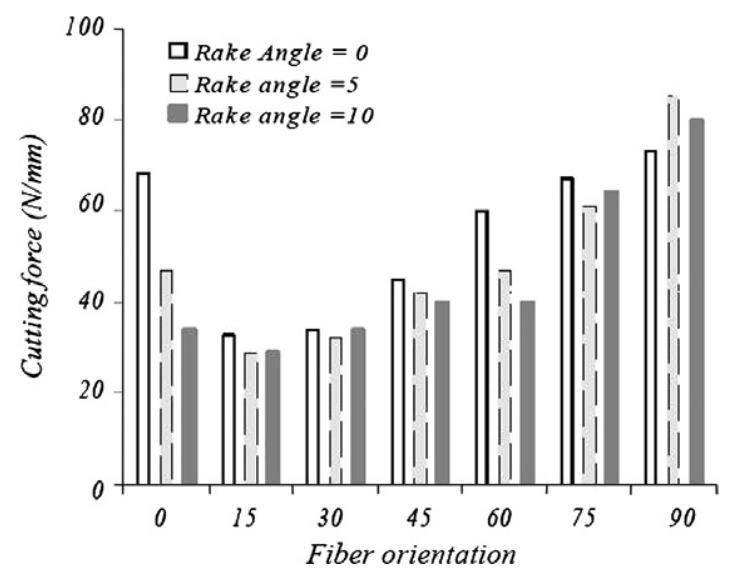

Fig. 12. Cutting forces vs. fiber orientation for different rake angle.

The effect of rake angle on damage is shown in Fig. 13. It is possible to deduce from damaged contours, comparing the lowest and highest values of the rake angle, that the damage is slightly increased when the rake angle is decreased, especially the penetration beneath the tool tip in case of higher values of fiber angle.

Also chip morphology is affected by the rake angle. It is possible to observe differences in the inclination of the primary zone, due to the relative position between the fibers and the rake surface (effective fiber orientation angle, which is the relative angle between the tool rake face and the fiber orientation [20]). When the rake angle increases, it is decreased the effective fiber inclination respect to the rake surface, and the mechanism of chip formation corresponds with the typical configuration of lower fiber inclination. Thus for low orientation angle it was observed the bending moment effect described in [32] more accentuated in case of rake angle equal to $0^{\circ}$ than in case of rake angle equal to $10^{\circ}$.

The interaction between tool and workpiece leads to the formation of a stressed zone ahead the tip. When the stress state reached the level of damage initiation, a crack was formed in front of the cutting edge. Progression of the crack originated an almost rectangular chip acting as a cantilever beam; the fracture of the chip took place at the cantilever support. Cracking damage was observed along the primary zone (oriented parallel to fiber) while compressive damage occurred at the outer contour [13]. This bending effect was softened as the orientation angle increases, due to the enhanced contribution of the fiber to strength in the direction normal to cutting speed direction. Thus the chip size diminished and evolved to triangular shape. This is the global effect observed in the simulations corresponding to a rake angle equal to $0^{\circ}$, generating smaller chips when compared with those carried out with a rake angle equal to $10^{\circ}$.

\subsection{Influence of cutting edge radius}

In metal cutting, rounded cutting edge is commonly related with increased cutting forces, due to the decreased effective rake angle in the rounded zone. Also large radius is associated with diminished quality of the machined surface. This effect is due to mechanical effects (decreased effective rake angle, enhanced zone of stagnation) and it is also related with thermal effects leading to increased residual stresses in the workpiece [33].

In case of composite cutting simulation based on a model that does not account for thermal phenomenon, the role of cutting edge radius is due to mechanical effects. Figs. 14 and 15 present the influence of cutting edge radius in cutting and thrust force: both forces are increased with the radius in all cases analyzed.

The influence of the rounded edge in damage and chip morphology can be appreciated in Fig. 16 for depth of cut $0.2 \mathrm{~mm}$. Chip configuration does not experienced significant changes with edge radius. When the radius is increased the cut is performed with decreased local effective radius. Fig. 16 shows that this effect is not very significant when the radius ranged from 0.05 to $0.15 \mathrm{~mm}$, being these values always lower than the depth of cut. This effect could be enhanced for larger values of the radius, it is commonly observed in metal cutting that strong changes in the chip morphology occurs when the ratio radius over depth of cut is larger than one.

However, the effect of cutting edge radius in the damage could not be considered negligible. Matrix crushing mode, dominant in the zone beneath the machined surface increases both in extension and depth with the radius. In the same way, matrix cracking, being the most significant mode in the area beneath and ahead the tool tip, increased in extension and depth with the radius. These results are important for current machining operations of composites in industry because null magnitude of cutting edge radius is never realizable, even for a very fresh tool, and evolves with cutting time. In a recent work [34] demonstrated the development of an evenly and smoothly distributed rounded abrasion wear pattern along the entire cutting edge of carbide tools in drilling carbon LFRP. This wear feature has only been named in literature rarely. Wear studies in drilling operations commonly focuses on flank wear evolution, however, a recent study related with the loss of mass in the drill, that could involve different simultaneous wear mechanisms, can be found in the literature [35]. 

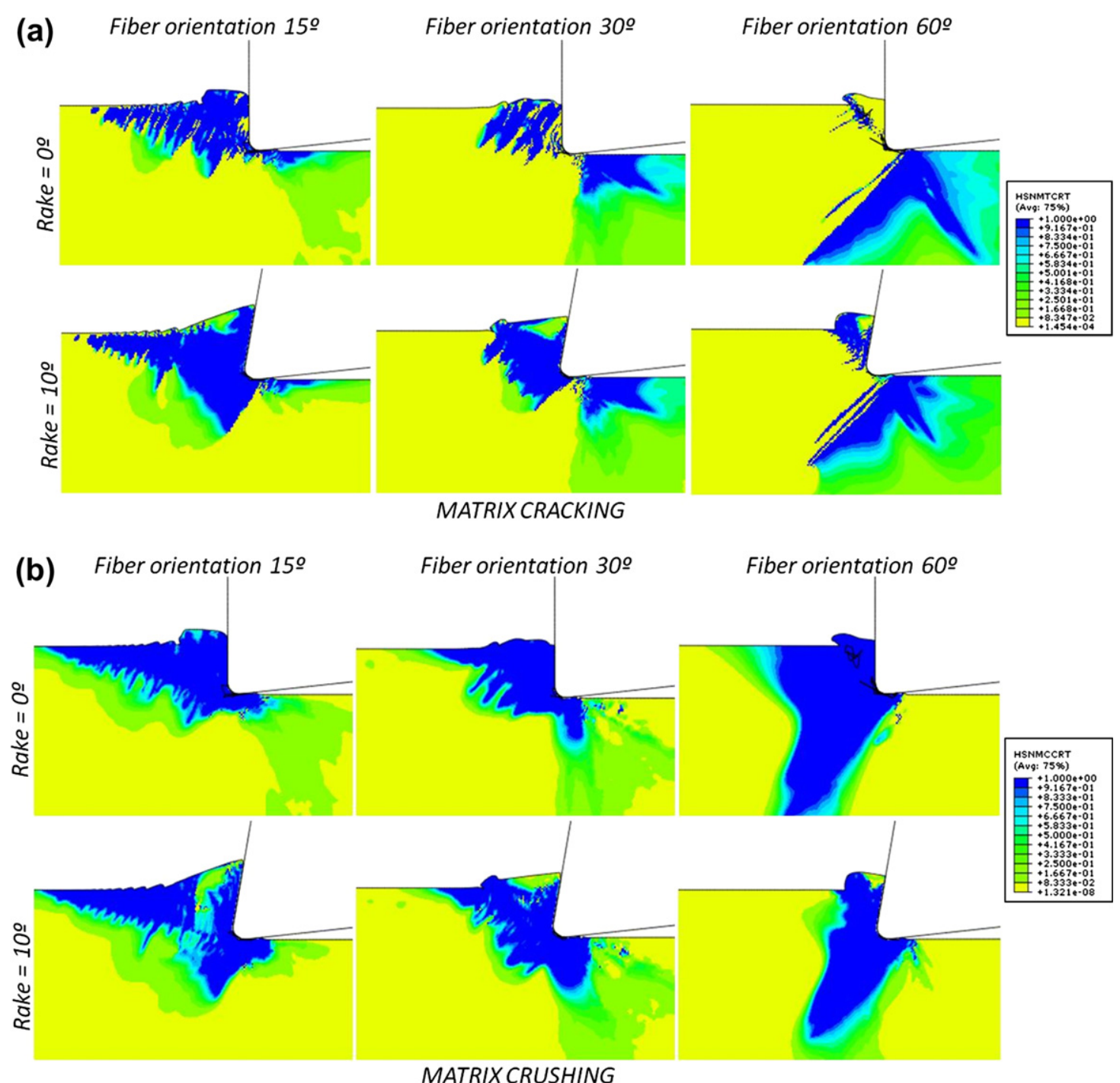

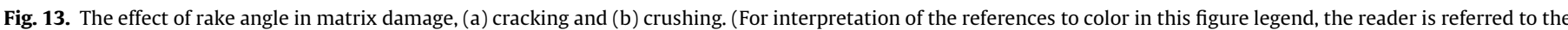
web version of this article.)
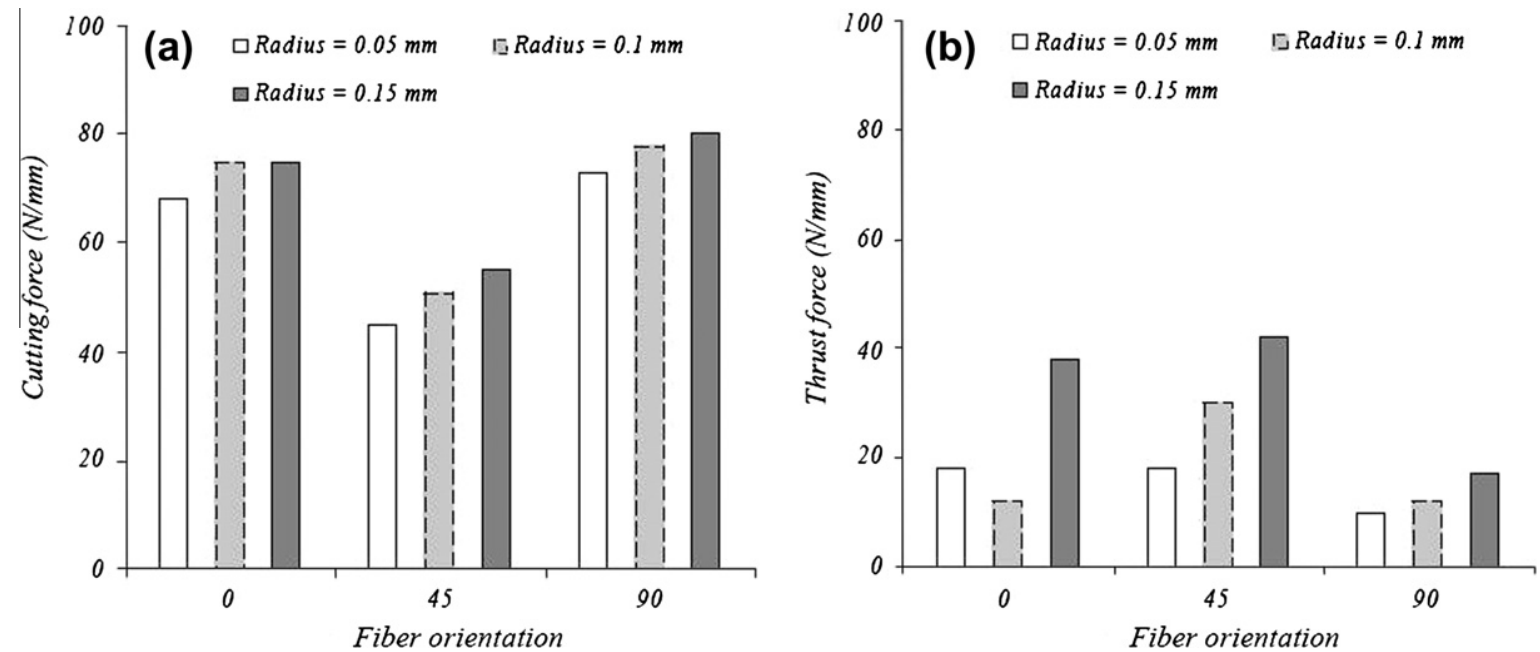

Fig. 14. Cutting and thrust force for different values of cutting edge radius (feed rate $0.2 \mathrm{~mm}$, rake angle $0^{\circ}$ ). 

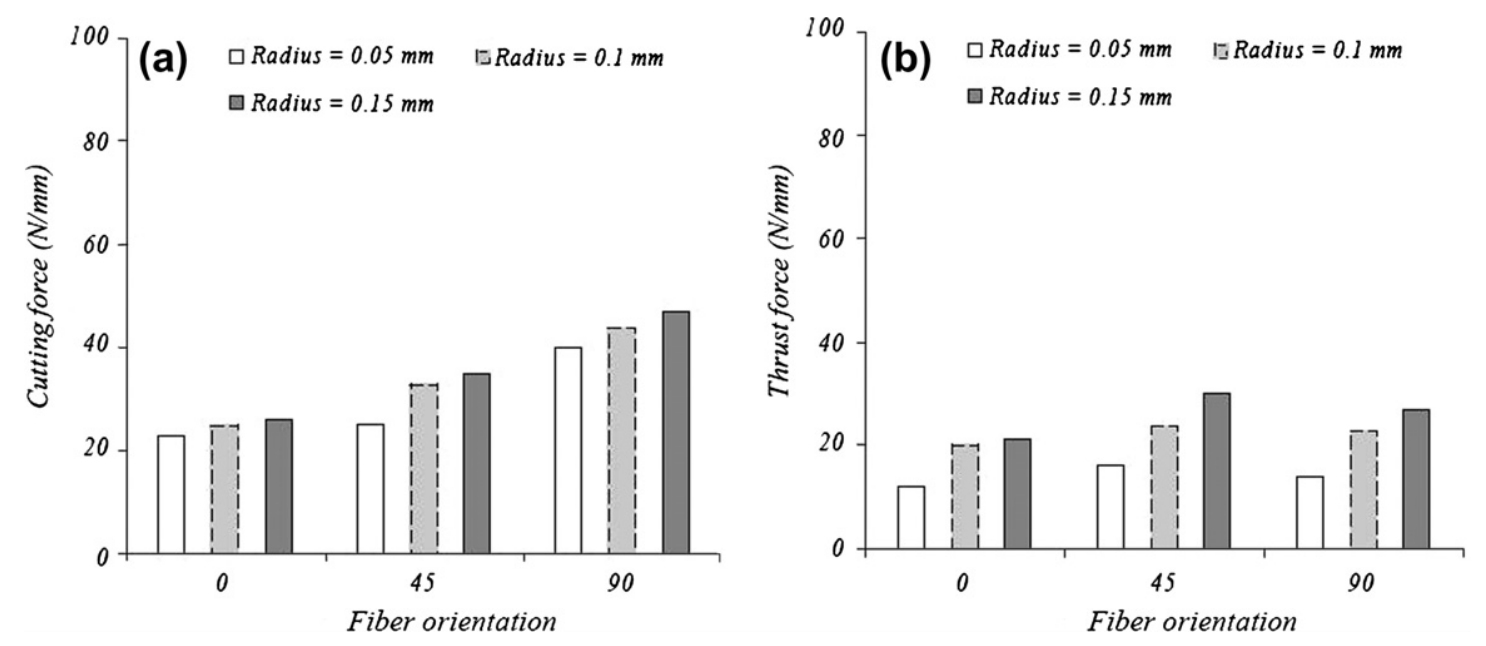

Fig. 15. Cutting and thrust force for different values of cutting edge radius (feed rate $0.1 \mathrm{~mm}$, rake angle $0^{\circ}$ ).

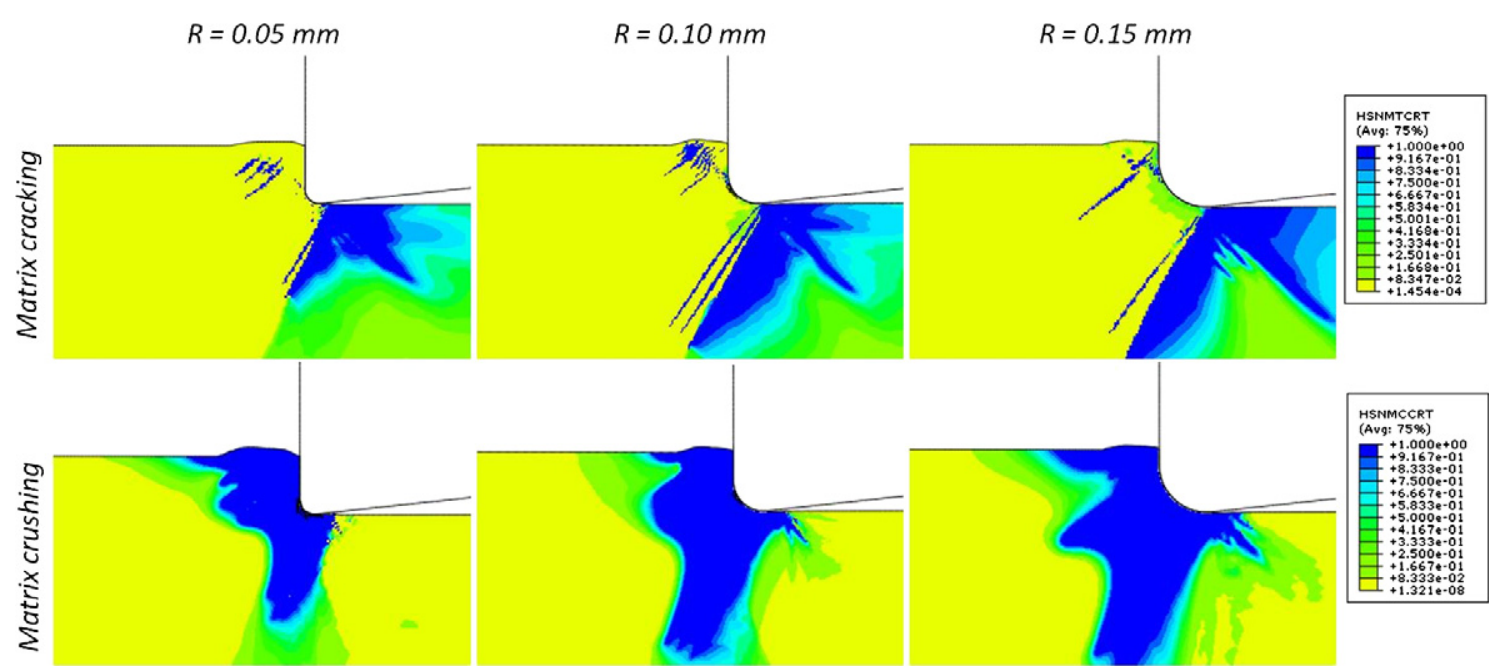

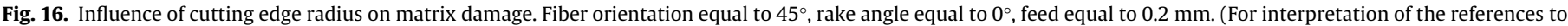
color in this figure legend, the reader is referred to the web version of this article.)

\section{Conclusions}

This paper is focused on the analysis of the influence of numerical parameters and tool geometry on the simulation of orthogonal cutting of LFRP composites. It has been demonstrated the influence of the mesh configuration (both element size and mesh orientation) on the numerical results. Also the influence of the energy in element breakage has been analyzed. This numerical parameter has a physical foundation, but due to the difficulty of its measurement and identification it is rarely reported in the literature. The level of energy controls the behavior of the composite leading to a brittle or ductile response during cutting, being directly related with the damage experienced by the workpiece.

The effect of the rake angle and the cutting edge radius of the tool were also analyzed. This parameters are crucial for the tool design because they are related with its durability (lower values of rake angle improve the robustness of the tool), the use of coatings (related with increased radius) or tool wear mechanisms (abrasion wear leading to increased cutting edge radius).

The numerical work was performed in terms of the analysis of predicted cutting and thrust forces, chip morphology and damage:
- Cutting and thrust forces are robust output variables which can be considered independent of the numerical parameters studied in the paper. Lower values of rake angle increases the difficulty of the cutting process leading to enhanced values of the forces. The increment of cutting edge radius also produces an increment of the forces. In fact the rounded cutting edge could be interpreted as a decreased effective rake angle.

- Chip morphology is strongly influenced by the level of energy needed to reach a complete element breakage. Chip morphology is also dependent on geometrical tool parameters. The rake angle interacts with the fiber orientation resulting in a modified inclination relative to the rake surface. The rounded cutting edge has slight effect on the chip morphology.

- Damage is the most sensible factor. Not only mesh size, shape and orientation influenced the predicted fields of damage. The damage distribution also changes significantly with the variation of the energy level needed for breakage: the lower is the energy, the more brittle is the composite and in consequence, the damage tends to be reduced to a small area surrounding the tool and beneath the machined surface. The role of cutting edge radius is especially important because the radius 
increment is directly related with enhanced damage. This result is crucial for industry, since abrasion due to the highly abrasive nature of the carbon fibers has been reported recently to be a significant mechanism of wear in drilling operations of these types of composite.

\section{Acknowledgements}

The authors are indebted for the financial support of this work, to the Ministry of Science and Innovation of Spain (under Project DPI2008-06746).

\section{References}

[1] Mkaddem A, El Mansori M. Finite element analysis when machining UGFreinforced PMCs plates: chip formation, crack propagation and induceddamage. J Mater Des 2009. doi:10.1016/j.matdes.2008.12.009.

[2] Nayak D, Bhatnagar N, Mahajan P. Machining studies of uni-directional glass fiber reinforced plastic (UD-GFRP) composites part 1: effect of geometrical and process parameters. Machining Sci Technol 2005;9:481-501.

[3] Bhatnagar N, Nayak D, Singh I, Chouhan H, Mahajan P. Determination of machining-induced damage characteristics of fiber reinforced plastic composite laminates. Mater Manuf Processes 2004;19(6):1009-23.

[4] Wang XM, Zhang LC. An experimental investigation into the orthogonal cutting of unidirectional fiber reinforced plastics. Int $\mathrm{J}$ Mach Tools Manuf 2003:43:1015-22.

[5] Mkaddem A, Demirci I, El Mansori M. A micro-macro combined approach using FEM for modelling of machining of FRP composites: cutting forces analysis. Compos Sci Technol 2008;68:3123-7.

[6] Nayak D, Bhatnagar N, Mahajan P. Machining studies of UD-FRP composites part 2: finite element analysis. Machining Sci Technol 2005;9:503-28.

[7] Venu Gopala Rao G, Mahajan P, Bhatnagar N. Micro-mechanical modeling of machining of FRP composites-cutting force analysis. Compos Sci Technol 2007;67:579-93.

[8] Arola D, Ramulu M. Orthogonal cutting of fiber-reinforced composites: a finite element analysis. Int J Mech Sci 1997;39:597-613.

[9] Ramesh MV, Seetharamu KN, Ganesan N, Shivkumar MS. Analysis of machining of FRPs using FEM. Int J Mach Tools Manuf 1998;38:1531-49.

[10] Mahdi M, Zhang L. An adaptive three-dimensional finite element algorithm for the orthogonal cutting of composite materials. J Mater Process Technol 2001;113:368-72.

[11] Mahdi M, Zhang L. A finite element model for the orthogonal cutting of fiber reinforced composite materials. J Mater Process Technol 2001;113:368-72.

[12] Arola D, Sultan MB, Ramulu M. Finite element modeling of edge trimming fiber-reinforced plastics. Trans ASME J Eng Mater Technol 2002;124:32-41.

[13] Santiuste C, Soldani X, Miguélez H. Machining FEM model of long fiber composites for aeronautical components. Compos Struct 2010;92:691-8.

[14] Iliescu D, Gehin D, Iordanoff I, Girot F, Gutiérrez ME. A discrete element method for the simulation of CFRP cutting. Compos Sci Technol 2009. doi:10.1016/j.compscitech.2009.09.00.
[15] Gururaja S, Ramulu M. Analytical formulation of subsurface stresses during orthogonal cutting of FRPs. Composites Part A 2010;41:1164-73.

[16] Barge M, Hamdi H, Rech J, Bergheau J-M. Numerical modelling of orthogonal cutting: influence of numerical parameters. J Mater Process Technol 2005;164-165:1148-53.

[17] Miguélez H, Zaera R, Rusinek A, Moufki A, Molinari A. Numerical modelling of orthogonal cutting: influence of cutting conditions and separation criterion. J Phys IV 2006;134:417-22.

[18] Hortig C, Svendsen B. Simulation of chip formation during high-speed cutting. J Mater Process Technol 2007;186:66-76.

[19] Soldani X, Muñoz-Sánchez A, Miguélez H, Molinari A. Numerical modeling of segmentation phenomenon in orthogonal cutting, In: CIRP 2nd International conference process machine interactions (Vancouver; 2010).

[20] Ramulu M, Kim D, Choi G. Frequency analysis and characterization in orthogonal cutting of glass fiber reinforced composites. Composites Part A 2003;34:949-62.

[21] Caprino G, De lorio I, Nele L, Santo L. Effect of tool wear on cutting forces in the orthogonal cutting of unidirectional glass fibre-reinforced plastics. Composites Part A 1996;27A:409-15.

[22] Hibbit, Karlson, Sorensen Inc. ABAQUS user's manual 6.4-1; 2003.

[23] Girot F, López de Lacalle LN, Lamikiz A, Iliescu D, Gutiérrez ME. Machinability aspects of polymer matrix composites in machining composites materials. New York: Wiley \& Sons; 2009.

[24] Mondelin Alexandre, Furet Benoit, Rech Jöel. Characterisation of friction properties between a laminated carbon fibres reinforced polymer and a monocrystalline diamond under dry or lubricated conditions. Tribol Int 2010;43:1665-73.

[25] Lasri L, Nouari M, El Mansori M. Modelling of chip separation in machining unidirectional FRP composites by stiffness degradation concept. Compos Sci Technol 2009;69:684-92.

[26] Hashin Z, Rotem AA. Fatigue criterion for fiber-reinforced materials. J Compos Mater 1973;7:448-64.

[27] Hashin Z. Failure criteria for unidirectional fiber composites. J Appl Mech 1980;47:329-34.

[28] Camanho PP, Dávila CG. Mixed-mode decohesion finite elements for the simulation of delamination in composite materials. NASA/TM-2002-211737; 2002, p. $1-37$.

[29] Rotem A. Residual flexural strength of FRP composite specimens subjected to transverse impact loading. SAMPE J 1988;24:19-25.

[30] Camanho PP, Matthews FL. A progressive damage model for mechanically fastened joints in composite laminates. J Compos Mater 1999;33:2248-80.

[31] Flanagan DP, Belytschko T. A uniform strain hexahedron quadrilateral with orthogonal hourglass control. Int J Numer Methods Eng 1981;17:679-706.

[32] Astakhov V. Metal cutting mechanics. CRC Press; 1999.

[33] Miguélez MH, Zaera R, Molinari A, Cheriguene R, Rusinek A. Residual stresses in orthogonal cutting of metals: the effect of thermomechanical coupling parameters and of friction. J Therm Stress 2009;32:269-89.

[34] Faraz Ali, Biermann Dirk, Weinert Klaus. Cutting edge rounding: an innovative tool wear criterion in drilling CFRP composite laminates. Int J Machine Tools Manuf 2009;49:1185-96.

[35] Khashaba UA, El-Sonbaty IA, Selmy AI, Megahed AA. Machinability analysis in drilling woven GFR/epoxy composites: part II - Effect of drill wear. Composites Part A 2010;41:1130-7. 